\title{
The evolving nature of chemical education: challenges and opportunities
}

"If the pace of change in education experienced during the past 20 years is considered to be fast, then change during the next 20 years could be supersonic."

Remember education in chemistry 20 years in the past, then imagine that education 20 years in the future. Two decades ago the internet did not exist and education was intended for everyone in the USA [1]. The library with its books, journals and documents was available for the user to obtain unknown information. To transfer information, the only storage device available was a photocopier or, perhaps, a note card onto which you wrote needed data. Undergraduate education at colleges and universities depended on information transfer in a classroom and the course sequence was prescribed in the USA with general chemistry preceding organic chemistry, which in turn preceded physical chemistry with analytical, biological and inorganic chemistries interwoven into a basic text-dependent framework [2]; similar regimentation was employed elsewhere [3]. Laboratories relied on sensory 'change' whether it was the color of an indicator in a titration, the heat generated when two substances were mixed or the odor from a product formed in a chemical reaction, and instrumentation was sometimes available for pattern recognition associated with chemical properties [4].

\section{"Students of the chemical sciences - and there will be fewer of them - may be programmed onto career pathways earlier in order to maximize their lifetime output..."}

Now consider what might be accepted as education in chemistry 20 years from now. If the pace of change in education experienced during the past 20 years is considered to be fast [5], then change during the next 20 years could be supersonic. The cost of education in the USA will have accelerated over this 20 -year period due to decreasing state and federal aid for education at college and university levels [6]. There will be increasing recognition that connectivity of information is individually programmable and that specific talent, such as problem solving and information retrieval, can be maximized.

"Laboratories could be simulated, with experiments designed on multiple levels that are reminiscent of the 'video games' of the distant past..."

Students of the chemical sciences - and there will be fewer of them - may be programmed onto career pathways earlier in order to maximize their lifetime output, and their sequence of lessons will be tailored to their individual career needs. Specialization for maximum advantage will be the dominant theme. The sequence of courses with chemistry content will look like 'Chemical Synthesis I and II' rather than their counterparts in organic and inorganic chemistry and 'Chemistry of Life Processes' will have replaced biochemistry/molecular biology courses [7]. 'Green chemistry' can be expected to be pervasive and integral in all undergraduate education [8]. Laboratories could be simulated, with experiments designed on multiple levels that are reminiscent of the 'video games' of the distant past [9]; however, technique development integral to specific careers will require continuation of the laboratory practicum. Online education will probably be mandatory for postdegree lifelong learning.

In 20 years, the chemical industry as we know it today will have fully morphed into component divisions of conglomerates that service the agriculture, construction, environment, food,

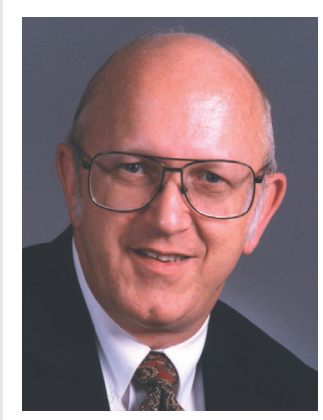

Michael P Doyle

Department of Chemistry and Biochemistry,

University of Maryland,

College Park,

MD 20742, USA

Tel.: + I 301 4051788

Fax: + I 30I 3142779

E-mail: mdoyle3@umd.edu 
health, government, information, manufacturing, materials and transportation sectors of the world economy. We see this even today, with titles such as 'chief analyst' and 'senior scientist', the title 'chemist' will have been replaced by those more closely aligned with specific job function. Even the pharmaceutical industry, for which organic chemistry has been the central science, will have migrated closer to biotechnology as its core science [10]. In order to secure and retain the most talented employees, industry will have entered into partnerships with select universities to enhance course content and ensure their employee's access to the 'state-of-the-art' [11]. The aptitude of students for research will be determined through experiences that often begin in high school but are universal in colleges and universities.

\section{“...the title 'chemist' will have been replaced by those more closely aligned with specific job function."}

Nowhere will there be greater challenges than in securing employment with advanced degrees in the chemical sciences, and if today's students are indicators, the pharmaceutical industry holds the greatest attraction [12]. If the scenario presented for the future is realistic, a student planning such a future will enter a program tailored to a career in the pharmaceutical sciences that will develop core competence in synthesis, analysis, biophysics and biotechnology. This is a different future from the one projected at most colleges and universities today and will require changes in academic planning and advising, course offerings and degree administration; but these should be no less possible than those that accompanied the integration of biochemistry and materials science into the undergraduate chemistry curriculum [2]. Whereas, in the past, employers of medicinal chemists looked to organic chemistry centers almost exclusively for new employees, today the difference between practitioners of organic and medicinal chemistry has narrowed.

\section{"...today the difference between practitioners of organic and medicinal chemistry has narrowed."}

The number of students obtaining an undergraduate degree in chemistry in the USA has increased nearly $25 \%$ over the past 10 years and the number of students obtaining their $\mathrm{PhD}$ degree has also increased [13]. However, job opportunities have shrunk substantially $[10,14]$ and there is uncertainty if or when there will be a recovery. In the meantime, there will be a backlog in employable personnel with graduate students and postdoctoral associates remaining in current positions and a diminished attraction for careers in chemistry in general and medicinal chemistry in particular. Projections for the near future are that job growth for all chemists is expected to be slower than the average for all professions [15]. At the same time, the pool for the best talent will be international and adaptability and communication skills will be as valuable as are technical skills in seeking employment. Those who are demonstrated problem solvers, possess excellent communication skills and are efficient and organized will be at the top of the applicant pool and the institutions from which they come will benefit substantially from their success.

\section{"The base message here is that chemical education will become more career directed and specialized."}

The base message here is that chemical education will become more career directed and specialized. Already, biochemistry is expected for all students in approved undergraduate programs in the USA [2] and one can expect that biotechnology will play an increasingly important role in the chemical sciences in the near future. Even today, in its summary of expected education and training for chemists, the US Bureau of Labor Statistics suggests the breadth of courses that students should experience: "in addition to taking required courses in analytical, inorganic organic and physical chemistry, undergraduate chemistry majors usually study biological sciences; mathematics; physics; and, increasingly, computer science" [15]. Undergraduate research has played an important role in the past in identifying students with high aptitude for problem solving $[16,17]$ and continued growth in demand and opportunities for this experience can be expected. Communication skills are fostered through undergraduate research experiences at most colleges and universities, with local and national research symposia routinely encouraged and funded; however, they are less visible 
in expectations and not as well funded within most graduate programs. The bottleneck for change in education generally exists in graduate programs and the major catalysts for change are funding agencies that support programmatic developments that are often associated with major funding initiatives. However, although the scenario presented is cautious and may be intimidating, the career advantages are wholesome and inviting.

\section{Bibliography}

1 McGrath EJ (Ed.). Universal Higher Education. McGraw Hill Book Co. NY, USA (1966).

2 Undergraduate Professional Training in Chemistry: ACS Guidelines and Evaluation Procedures for Bachelor's Degree Programs. Committee on Professional Training, American Chemical Society, Washington DC, USA (2008).

3 Innovative Methods of Teaching and Learning Chemistry in Higher Education. Eilks I, Byers B (Eds). Royal Society of Chemistry, Cambridge, UK (2009).

4 Taft HL. National Curriculum Survey of College General Chemistry. J. Chem. Educ. 74(5), 595-599 (1997).

5 Douglass JA. The Waning of America's Higher Education Advantage: International Competitors Are No Longer Number Two and Have Big Plans in the Global Economy. UC Berkeley, Center for Studies in Higher Education, Berkeley, CA, USA (2006).

\section{Financial \& competing interests disclosure}

The author has no relevant affliations or financial involvement with any organization or entity with a financial interest in or financial conflict with the subject matter or materials discussed in the manuscript. This includes employment, consultancies, honoraria, stock ownership or options, expert testimony, grants or patents received or pending, or royalties.

No writing assistance was utilized in the production of this manuscript.

6 Trombley W. The Rising Price of Higher Education. National Center for Public Policy and Higher Education, San Jose, CA, USA (2003).

7 Echegoyen L. NSF Division of Chemistry Programs Realigned. National Science Foundation, Arlington, VA, USA (2009).

8 Fortunak JM. Current and future impact of green chemistry on the pharmaceutical industry. Future Med. Chem. 1(4), 571-575 (2009).

9 Yaron D, Cuadros J, Leinhardt G, Evans KL, Karabinos M. Virtual laboratories and scenes to support chemistry instruction. In: About Invention and Impact: Building Excellence in Undergraduate STEM (Science, Technology, Engineering, and Mathematics) Education. Proceedings from National Science Foundation Course, Curriculum, and Laboratory Improvement (NSF-CCLI) program conference, Arlington, VA, USA, 2004(2005).

10 Ojima I. Medicinal chemistry at a crossroads: challenges and new possibilities. Future Med. Chem. 1(3), 401-403 (2009).
11 Niedergassel B, Leker J. Open innovation: chances and challenges for the pharmaceutical industry. Future Med. Chem. 1(7), 1197-1200 (2009).

12 Balbes LM. Nontraditional Careers for Chemists: New Formulas in Chemistry. Oxford University Press. Oxford, England, UK (2006).

13 Hanson DJ. Gains in chemistry grads persist. Chem. Eng. News 87(47), 39-48 (2009).

14 Thayer AM. Drug firms face down economy. Chem. Eng. News 87(20), 24-26 (2009).

15 Occupational Outlook Handbook 2010-2011. Chemists and Materials Scientists. Bureau of Labor Statistics, Washington DC, USA. (2009).

16 Committee on Undergraduate Biology Education to Prepare Research Scientists for the $21^{\text {st }}$ Century. Bio 2010. The National Academies Press, Washington DC, USA(2003).

17 Academic Excellence: the Role of Research in the Physical Sciences at Undergraduate Institutions. Doyle MP (Ed.). Research Corporation, Tucson, AZ, USA (2000). 